\title{
Myocyte Enhancer Factor 2A and 2D Undergo Phosphorylation and Caspase-Mediated Degradation during Apoptosis of Rat Cerebellar Granule Neurons
}

\author{
Mingtao Li, ${ }^{1}$ Daniel A. Linseman, ${ }^{1}$ Melissa P. Allen, ${ }^{2}$ Mary Kay Meintzer, ${ }^{1}$ Xiaomin Wang, ${ }^{1}$ Tracey Laessig, ${ }^{1}$ \\ Margaret E. Wierman, ${ }^{2}$ and Kim A. Heidenreich ${ }^{1}$ \\ Departments of ${ }^{1}$ Pharmacology and ${ }^{2}$ Medicine, University of Colorado Health Sciences Center and the Denver Veterans \\ Affairs Medical Center, Denver, Colorado 80262
}

Myocyte enhancer factor 2 (MEF2) proteins are important regulators of gene expression during the development of skeletal, cardiac, and smooth muscle. MEF2 proteins are also present in brain and recently have been implicated in neuronal survival and differentiation. In this study we examined the cellular mechanisms regulating the activity of MEF2s during apoptosis of cultured cerebellar granule neurons, an established in vitro model for studying depolarization-dependent neuronal survival. All four MEF2 isoforms (A, B, C, and D) were detected by immunoblot analysis in cerebellar granule neurons. Endogenous MEF2A and MEF2D, but not MEF2B or MEF2C, were phosphorylated with the induction of apoptosis. The putative sites that were phosphorylated during apoptosis are functionally distinct from those previously reported to enhance MEF2 transcription. The increased phosphorylation of MEF2A and MEF2D was followed by decreased DNA binding, reduced transcriptional activity, and caspase-dependent cleavage to fragments containing $\mathrm{N}$-terminal DNA binding domains and C-terminal transactivation domains. Expression of the highly homologous $\mathrm{N}$ terminus of MEF2A (1-131 amino acids) antagonized the transcriptional activity and prosurvival effects of a constitutively active mutant of MEF2D (MEF2D-VP16). We conclude that MEF2A and MEF2D are prosurvival factors with high transcriptional activity in postmitotic cerebellar granule neurons. When these neurons are induced to undergo apoptosis by lowering extracellular potassium, MEF2A and MEF2D are phosphorylated, followed by decreased DNA binding and cleavage by a caspase-sensitive pathway to $\mathrm{N}$-terminal fragments lacking the transactivation domains. The degradation of MEF2D and MEF2A and the generation of MEF2 fragments that have the potential to act as dominant-inactive transcription factors lead to apoptotic cell death.

Key words: MEF2; neurons; apoptosis; transcription; caspase; cerebellum
Myocyte enhancer factor $2(\mathrm{MEF} 2)$ transcription factors are members of the MADS (MCM1-agamous-deficiens-serum response factor) family of transcription factors (Yu et al., 1992; Naya and Olson, 1999). A hallmark of MADS-box proteins is their combinational association with other MADS domain factors, as well as other heterologous classes of transcriptional regulators (Shore and Sharrocks, 1995). Mammalian MEF2 proteins are encoded by four genes (MEF2A, MEF2B, MEF2C, and MEF2D), each of which gives rise to alternatively spliced transcripts (Yu et al., 1992; Leifer et al., 1993; Martin et al., 1994). The MEF2 family of genes is highly expressed in cells of muscle lineage, where they have been shown to be important regulators of gene expression during the development of skeletal, cardiac, and smooth muscle (McDermott et al., 1993; Martin et al., 1994; Molkentin et al., 1996). In these tissues the MEF2 proteins interact with myogenic basic helix-loop-helix transcription factors such as MyoD to activate myogenesis (Molkentin and Olson, 1996; Ornatsky et al., 1997).

\footnotetext{
Received Feb. 9, 2001; revised June 15, 2001; accepted June 21, 2001.

This research was supported by United States Army Medical Research and Materiel Command Grant DAMD17-99-1-9481, by National Institutes of Health Grant NS38619-01A1, and by a Veterans Affairs Merit Award and Research Enhancement Award Program Award to KA.H.

M.L. and D.A.L. contributed equally to this manuscript.

Correspondence should be addressed to Dr. Kim A. Heidenreich, Denver Veterans Affairs Medical Center-111H, 1055 Clermont Street, Denver, CO 80220. E-mail: kim.heidenreich@uchsc.edu.

Copyright (ㄷ) 2001 Society for Neuroscience $0270-6474 / 01 / 216544-09 \$ 15.00 / 0$
}

All MEF2 family members also are highly expressed in neurons of the CNS (Leifer et al., 1993, 1994; McDermott et al., 1993; Ikeshima et al., 1995; Lyons et al., 1995; Mao et al., 1999). Recent in vitro findings support the hypothesis that MEF2 transcription factors regulate neuronal survival and development. In cultures of cerebral cortical neurons in which proliferating precursor cells and postmitotic differentiating neurons can be distinguished, MEF2C is expressed selectively in newly generated postmitotic neurons and is not detectable in BrdU-positive precursor cells (Mao et al., 1999). Transfection of postmitotic cortical neurons with different $\mathrm{MEF} 2 \mathrm{C}$ mutants demonstrated that $\mathrm{MEF} 2 \mathrm{C}$ is required for the survival of these neurons. In postnatal day 19 (P19) neuronal precursor cells, the expression of MEF2 induces a mixed neuronal/myogenic phenotype (Okamoto et al., 2000). During retinoic acid-induced neurogenesis of these cells, a dominant-negative form of $\mathrm{MEF} 2 \mathrm{C}$ enhances apoptosis but does not affect cell division. On the other hand, P19 cells induced to undergo apoptosis can be rescued from cell death by the expression of constitutively active MEF2C. In addition, overexpression of $\mathrm{MEF} 2 \mathrm{C}$ in $\mathrm{P} 19$ cells results in induction of neurofilament protein, the nuclear antigen $\mathrm{NeuN}$, and MASH-1, a neuralspecific transcription factor known to interact with MEF2s (Skerjanc and Wilton, 2000). These data suggest that MEF2 proteins regulate neuronal development by promoting survival and inducing differentiation.

In the present study we examined the mechanisms regulating the activity of MEF2 proteins during apoptosis of cultured rat 
cerebellar granule neurons, a well established model of depolarization-dependent neuronal survival. We provide evidence that MEF2A and MEF2D are prosurvival factors with high DNA binding and transcriptional activity in postmitotic cerebellar granule neurons. When these neurons are induced to undergo apoptosis by lowering extracellular potassium, MEF2A and MEF2D are phosphorylated. The phosphorylation of MEF2D and MEF2A is followed by decreased DNA binding and cleavage by a caspase-sensitive pathway to N-terminal MEF2 fragments that lack the transactivation domain. The decreased DNA binding of MEF2s and the formation of MEF2 fragments that can act as dominant-inactive transcription factors are sufficient to block the prosurvival effects of MEF2s and induce apoptosis in mature cerebellar granule neurons.

\section{MATERIALS AND METHODS}

Materials. The MEF2A antibody is an affinity-purified rabbit polyclonal antibody that was raised to a peptide corresponding to codons 487-507 of human MEF2A purchased from Santa Cruz Biotechnology (Santa Cruz, $\mathrm{CA}$ ). According to the manufacturer, this antibody may cross-react to a small extent with MEF2C. The affinity-purified rabbit polyclonal MEF2C antibody, a gift from John Schwarz (University of Texas Medical School, Houston, TX), was raised against an isoform-specific peptide representing codons 300-316 of human MEF2C and is specific for MEF2C (Firulli et al., 1996). The rabbit polyclonal antibody to MEF2B was raised against a polyhistidine fusion protein corresponding to codons 234-365 of human MEF2B and was kindly provided by Dr. Ron Prywes (Columbia University, NY). Antibody to MEF2D is a monoclonal antibody raised against a peptide corresponding to codons 346-511 of mouse MEF2D purchased from Transduction Laboratories (Lexington, KY). The dominant-inactive MEF2 mutant pcDNA3-MEF2A131 was kindly provided by Dr. Prywes. The dominant-active MEF2 mutant pCMVMEF2D-VP16 was a gift from Dr. John C. McDermott (York University, Toronto, Ontario, Canada). The pGL2-MEF2-Luc reporter plasmid (Lemercier et al., 2000) was provided by Dr. Saadi Khochbin (INSERM, France). The caspase-3 antibody was purchased from Santa Cruz Biotechnology, and the polyclonal anti- $\beta$-galactosidase $(\beta$-gal) antibody was purchased from 5 Prime $\rightarrow 3$ Prime (Boulder, CO). Cy3-conjugated goat antibody to rabbit IgG was purchased from Chemicon (Temecula, CA). The caspase inhibitors YVAD-CHO, DEVD-FMK, and ZVAD-FMK were obtained from Calbiochem (La Jolla, CA). $\left[\alpha-{ }^{32} \mathrm{P}\right] \mathrm{CTP}$ (3000 $\mathrm{Ci} / \mathrm{mmol}$ ) was purchased from Amersham Pharmacia Biotechnology (Piscataway, NJ).

Neuronal cell culture. Rat cerebellar granule neurons were prepared from 7- to 8-d-old Sprague Dawley rat pups (15-19 gm) as described previously (Li et al., 2000). Briefly, neurons were seeded at a density of $2.0 \times 10^{6}$ cells $/ \mathrm{ml}$ in basal modified Eagle's (BME) medium containing $10 \%$ fetal bovine serum, $25 \mathrm{~mm} \mathrm{KCl}, 2 \mathrm{~mm}$ glutamine, and penicillin (100 $\mathrm{U} / \mathrm{ml}) /$ streptomycin $(100 \mu \mathrm{g} / \mathrm{ml})$. Cytosine arabinoside $(10 \mu \mathrm{M})$ was added to the culture medium $24 \mathrm{hr}$ after plating to limit the growth of non-neuronal cells. With the use of this protocol, $95-99 \%$ of the cultured cells were granule neurons. Transfections were performed at day 5-6 in culture, and experiments were performed after $7 \mathrm{~d}$ in culture. Apoptosis was induced by removing the serum and reducing the extracellular potassium concentration from 25 to $5 \mathrm{~mm}$. Control cultures were treated identically but were maintained in serum-free medium supplemented with $25 \mathrm{~mm} \mathrm{KCl}$.

Western blot analysis. Western blot analysis was performed as described previously (Li et al., 2000). Briefly, neurons were lysed by adding SDS sample buffer [62.5 mM Tris-HCl, $\mathrm{pH} 6.8,2 \%$ (w/v) SDS, $10 \%$ glycerol, $50 \mathrm{~mm}$ DTT, and $0.1 \%$ (w/v) bromphenol blue]. The samples were resolved by SDS-PAGE with the use of either 7.5 or $12 \%$ acrylamide gels, as indicated in the legends. Proteins were transferred to Hybond-P membranes (polyvinylidene difluoride). The membranes were incubated with anti-MEF2A (1:5000), anti-MEF2D (1:1000), anti-MEF2C (1:1000), and anti-MEF2B (1:500). After incubation with the primary antibodies the filters were washed and then incubated with the respective horseradish peroxidase (HRP)-conjugated anti-rabbit or anti-mouse antibody (Amersham Pharmacia Biotech). Then the blots were washed and subsequently were developed with an enhanced chemiluminescence system (Amersham Pharmacia Biotech) and exposed to Kodak autoradio- graphic film. Quantitation was performed with the Bio-Rad Quantity One software (Hercules, CA).

Preparation of nuclear extracts from cerebellar granule neurons. After $7 \mathrm{~d}$ in culture the cerebellar granule neurons were rinsed two times in serum-free $\mathrm{BME}$ containing $25 \mathrm{mM} \mathrm{KCl}$ and then maintained in 25 or 5 $\mathrm{mM} \mathrm{KCl}$ medium in the absence or presence of caspase inhibitors. Neurons that did not receive inhibitors received the control vehicle dimethyl sulfoxide (DMSO). After the indicated times the neurons (100 $\mathrm{mm}$ dishes) were washed with ice-cold PBS and detached from culture dishes by a cell scraper in $0.5 \mathrm{ml}$ of buffer $\mathrm{A}$ [ $0.25 \mathrm{M}$ sucrose and (in $\mathrm{mM}$ ) 15 Tris, pH 7.9, $60 \mathrm{KCl}, 2$ EDTA, pH 8.0, 0.5 EGTA, $15 \mathrm{NaCl}, 1.0$ $\mathrm{Na}_{3} \mathrm{VO}_{4}, 50 \mathrm{NaF}, 0.5$ spermidine, 1 DTT, 1 benzamidine, and 0.5 PMSF plus $20 \mu \mathrm{g} / \mathrm{ml}$ leupeptin, $0.76 \mu \mathrm{g} / \mathrm{ml}$ pepstatin, and $2 \mu \mathrm{M}$ aprotinin]. The cells were centrifuged at $250 \times g$ for $5 \mathrm{~min}$. The pellets were washed twice in buffer A and then homogenized with 15 strokes of a tight-fitting Dounce homogenizer to release the nuclei. Then the homogenate was centrifuged at $14,000 \times g$ for $15 \mathrm{sec}$ to pellet the nuclei. The supernatants were removed, and the pellets were resuspended in buffer $\mathrm{C}$ [(in mM) 20 HEPES, pH 7.9, $500 \mathrm{KCl}, 1.5 \mathrm{MgCl}_{2}, 1$ EDTA, pH 8.0, $1.0 \mathrm{Na}_{3} \mathrm{VO}_{4}, 50$ $\mathrm{NaF}, 1.0$ DTT, 1 benzamidine, and 0.5 PMSF plus $20 \mu \mathrm{g} / \mathrm{ml}$ leupeptin, $0.76 \mu \mathrm{g} / \mathrm{ml}$ pepstatin, $25 \%$ glycerol, and $10 \mu \mathrm{M}$ aprotinin]. Nuclear proteins were extracted at $4^{\circ} \mathrm{C}$ for $45 \mathrm{~min}$, and insoluble nuclei were precipitated by centrifugation at $14000 \times g$ for $15 \mathrm{~min}$. Supernatants were dialyzed against a buffer containing $10 \%$ glycerol and (in mM) 10 Tris, pH 7.9, $5 \mathrm{MgCl}_{2}, 50 \mathrm{KCl}, 1$ EDTA, pH 8.0, $1.0 \mathrm{Na}_{3} \mathrm{VO}_{4}, 50 \mathrm{NaF}, 1 \mathrm{DTT}$, $1 \mathrm{PMSF}$, and 1 benzamidine for $3 \mathrm{hr}$ at $4^{\circ} \mathrm{C}$. The extracts were quantified for protein content by the BCA method (Pierce, Rockford, IL) and frozen in small aliquots at $-70^{\circ} \mathrm{C}$.

Electrophoretic mobility shift assays. Nuclear extracts from cerebellar granule neurons $(10 \mu \mathrm{g})$ were incubated with double-stranded oligonucleotides corresponding to the muscle creatine kinase MEF2 site 5'CGGATCGCTCTAAAAATAACCCTGTCG-3' (Amacher et al., 1993) or to a mutant oligonucleotide containing $\mathrm{C} \rightarrow \mathrm{G}$ and $\mathrm{A} \rightarrow \mathrm{C}$ substitutions at the two italicized residues. The oligomers were end-labeled with the Klenow fragment of DNA polymerase I (Life Technologies, Gaithersburg, MD) and $\left[\alpha-{ }^{32} \mathrm{P}\right] \mathrm{CTP}$ to a specific activity of $10,000-30,000 \mathrm{cpm} /$ ng. Binding reactions were performed for $20 \mathrm{~min}$ at $4^{\circ} \mathrm{C}$ in $1 \mathrm{~mm}$ dithiothreitol, $2.5 \mathrm{~mm} \mathrm{MgCl}_{2}, 10 \%$ glycerol, $0.1 \mathrm{mg} / \mathrm{ml}$ bovine serum albumin, $30 \mathrm{ng} / \mu \mathrm{l}$ of poly(dI-dC), $20 \mathrm{~mm}$ HEPES, $\mathrm{pH} 7.9$, and 50 $100,000 \mathrm{cpm}$ of oligomer in a total volume of $20 \mu \mathrm{l}$. For the supershift analysis, $1 \mu \mathrm{l}$ of specific antisera or preimmune serum was added to the nuclear extracts for $20 \mathrm{~min}$ at $4^{\circ} \mathrm{C}$, followed by another $20 \mathrm{~min}$ in the presence of labeled oligomers. The protein-DNA complexes were analyzed on $5 \%$ nondenaturing polyacrylamide gels containing $3 \%$ glycerol and $0.25 \times$ TBE ( $90 \mathrm{M}$ Tris borate, $1 \mathrm{~mm}$ EDTA) in the cold room. After electrophoresis the gels were dried and exposed to film at $-70^{\circ} \mathrm{C}$.

Transfection assays and reporter gene expression. Cerebellar granule neurons were transfected by a calcium phosphate coprecipitation method described previously (Li et al., 2000). Neurons were transfected with $1 \mu \mathrm{g}$ of MEF2-luciferase expression plasmids (pGL2-MEF2-luc) and/or 1-3 $\mu \mathrm{g}$ of MEF2D expression plasmids (pCMV-MEF2D-VP16, pcDNA3MEF2A131) and $1 \mu \mathrm{g}$ of pCMV- $\beta$-gal as an internal control for transfection efficiency. The total amount of DNA for each transfection was kept constant $(7 \mu \mathrm{g} / \mathrm{ml})$ by using the empty vector pcDNA3. Neurons were kept in conditioned medium after transfection for $2 \mathrm{hr}$; then the medium was replaced with BME containing 25 or $5 \mathrm{mM} \mathrm{KCl}$. After $4 \mathrm{hr}$ the cell extracts were prepared with reporter lysis buffer (Promega, Madison, WI), and the activities of luciferase and $\beta$-galactosidase were measured with the Luciferase Assay System (Promega) and the $\beta$-galactosidase Enzyme Assay System (Promega), respectively.

Quantitation of apoptosis in transfected neurons. Neurons were transfected as described previously ( $\mathrm{Li}$ et al., 2000). Plasmids (pCMVMEF2D-VP16, pCMV-MEF2D-VP16 plus pcDNA3-MEF2A131, and pCMV-LacZ) were added to the transfection media at a final concentration of 4-5 $\mu \mathrm{g} / \mathrm{ml}$. The total amount of DNA for each transfection was kept constant by using the empty vector pcDNA3. After transfection the neurons were switched to a medium containing 25 or $5 \mathrm{~mm} \mathrm{KCl}$. Then 16 hr later the cells were immunostained with a polyclonal antibody to $\beta$-galactosidase (1:500 dilution), followed by a Cy3-conjugated goat antibody to rabbit $\operatorname{IgG}(1: 500)$ to identify cells expressing $\beta$-galactosidase. To visualize the nuclei of transfected neurons, we included the DNA dye Hoechst $33258(5.0 \mu \mathrm{g} / \mathrm{ml})$ in the wash after the secondary antibody incubation. Apoptosis was quantified by scoring the percentage of cells in the $\beta$-galactosidase-expressing cell population with condensed or fragmented nuclei. So that we could obtain unbiased counting, cells $(\sim 500)$ 
were scored blindly without knowledge of their previous treatment. Experiments were performed in triplicate.

\section{RESULTS}

MEF2 protein expression and phosphorylation state in control and apoptotic cerebellar granule neurons

Primary cerebellar granule neurons represent a widely used in vitro model system that mimics the trophic action of neuronal activity that is seen in the developing nervous system (D'Mello et al., 1993; Miller et al., 1997). Thus, elevated levels of extracellular potassium promote neuronal survival by opening L-type voltagesensitive calcium channels, leading to an influx of calcium into neurons. Lowering of extracellular potassium decreases calcium influx and promotes neuronal cell death by an apoptotic mechanism.

Western analysis indicated that all four members of the MEF2 superfamily of transcription factors were present in cerebellar granule cells (Fig. 1A). When neurons were induced to undergo apoptosis by lowering extracellular potassium, there were selective shifts in the mobility of MEF2A (Fig. $1 A$, top) and MEF2D (Fig. $1 A$, bottom) on SDS gels. The mobility shifts were detected in neuronal cell lysates as early as $30 \mathrm{~min}$ and sustained to $8 \mathrm{hr}$. The shifts in mobility of MEF2A and MEF2D were enhanced when the samples were electrophoresed for longer times through higher resolution gels (Fig. $1 B$ ). Treatment of neuronal protein extracts with calf intestinal alkaline phosphatase before electrophoresis reversed the mobility shift of MEF2A and MEF2D seen in the low potassium conditions, confirming that the shifts in mobility of MEF2A and MEF2D were attributable to enhanced serine/threonine phosphorylation (Fig. $1 C$ ). The phosphorylation sites responsible for the increase in phosphorylation seen on lowering intracellular calcium are functionally different from those previously reported to enhance transcription. Both a p38 inhibitor (10 $\mu \mathrm{M}$ SB203580) and a MEK inhibitor (10 $\mu \mathrm{M}$ PD98059) failed to block the increase in phosphorylation seen with the induction of apoptosis (data not shown). The relative intensities of the slower-migrating MEF2A and MEF2D proteins decreased after 4 and $8 \mathrm{hr}$ in low potassium medium (Fig. $1 A$, lanes 6, 8), whereas the faster-migrating MEF2 proteins observed under depolarizing conditions remained constant, suggesting a link between MEF2 phosphorylation and degradation.

\section{MEF2D transcriptional activity is regulated by extracellular potassium}

The transcriptional activity of MEF2 proteins in cerebellar granule neurons was measured with a luciferase reporter plasmid that contains two MEF2 consensus sites, followed by the luciferase reporter gene (Lemercier et al., 2000). Cerebellar granule neurons grown in the presence of depolarizing potassium $(25 \mathrm{~mm})$ demonstrated high endogenous MEF2-driven luciferase activity (Fig. $2 A$ ). After the potassium was lowered to $5 \mathrm{~mm}$ for $4-8 \mathrm{hr}$, the transcriptional activity of the MEF2 reporter was decreased by $\sim 90 \%(p<0.05)$ (Figure $2 A)$. Incubation in $5 \mathrm{~mm}$ potassium for $4 \mathrm{hr}$, followed by the readdition of $25 \mathrm{~mm}$ potassium for an additional $4 \mathrm{hr}$, restored $\sim 50 \%$ of the MEF2 transcriptional activity (Fig. $2 A$ ). Similarly, the readdition of $25 \mathrm{~mm}$ potassium also reversed the mobility shift in MEF2D (Fig. 2B), suggesting that phosphorylation of MEF2D during apoptosis is associated with the observed decrease in MEF2 transcriptional activity. The fact that only a partial recovery of MEF2-driven luciferase activity was observed in the above experiment could be accounted for by the significant degradation of MEF2D that had occurred after
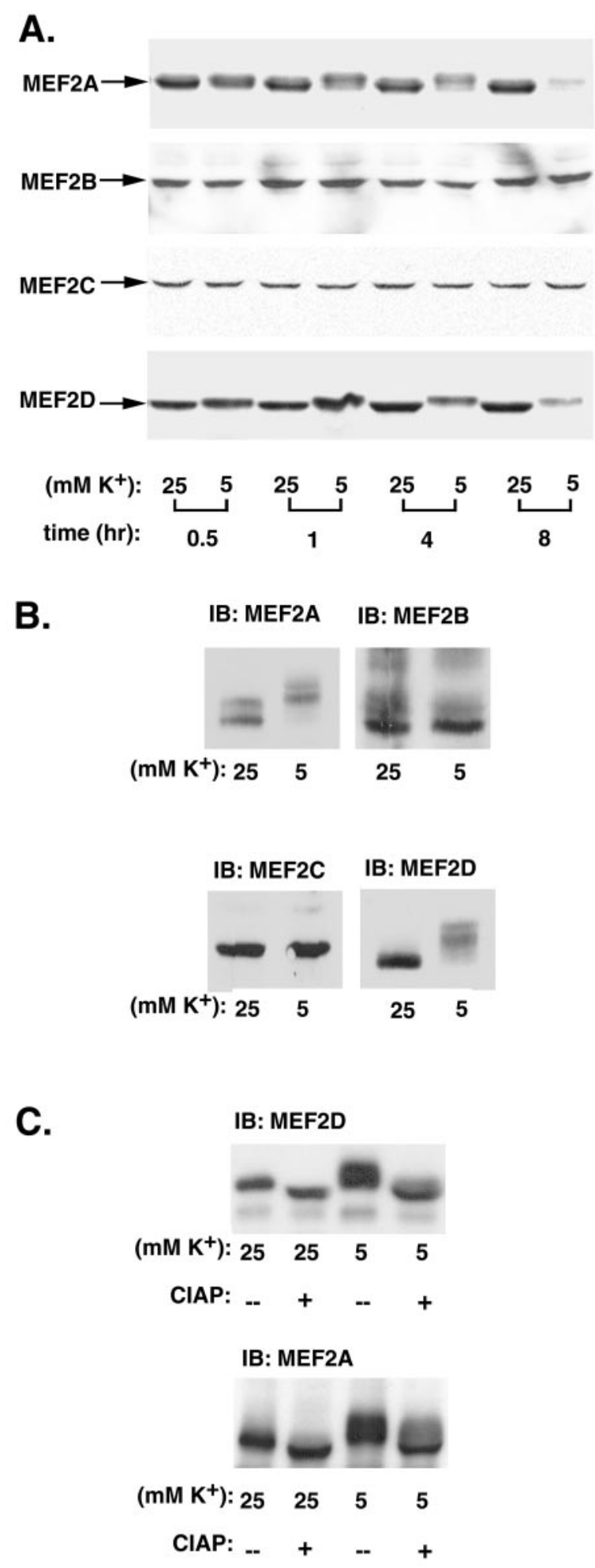

Figure 1. MEF2D and MEF2A, but not MEF2B and MEF2C, are phosphorylated and degraded during the apoptosis of cerebellar granule neurons. $A$, Cerebellar granule neurons (day 7) were placed in serum-free medium containing 25 or $5 \mathrm{mM} \mathrm{KCl}$ for the indicated times. Neuronal cell lysates were resolved on $7.5 \%$ SDS-acrylamide gels and subjected to Western analysis with the use of specific antibodies to MEF2A, MEF2B, $M E F 2 C$, and MEF2D. Data are representative of three separate experiments. $B$, Cell extracts were prepared as described above and analyzed on higher resolution gels. $C$, Cell extracts were incubated in the absence or presence of calf intestinal alkaline phosphatase $(C I A P ; 10 \mathrm{U} / \mathrm{ml})$ before gel electrophoresis. 


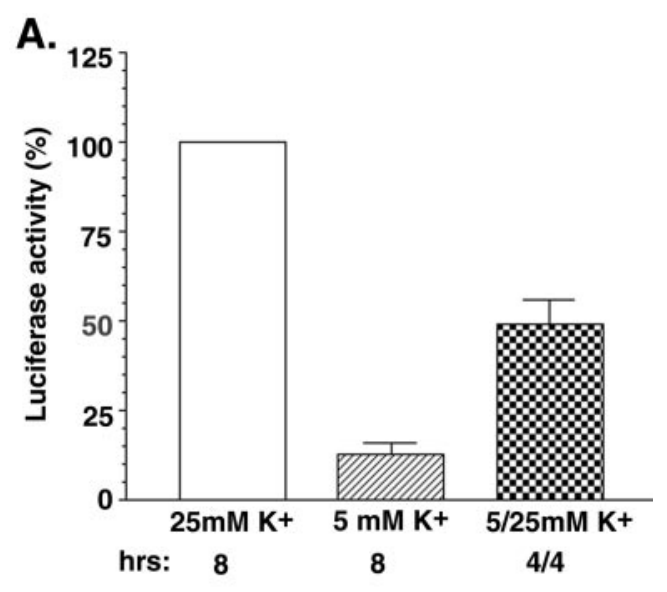

B. IB: MEF2D
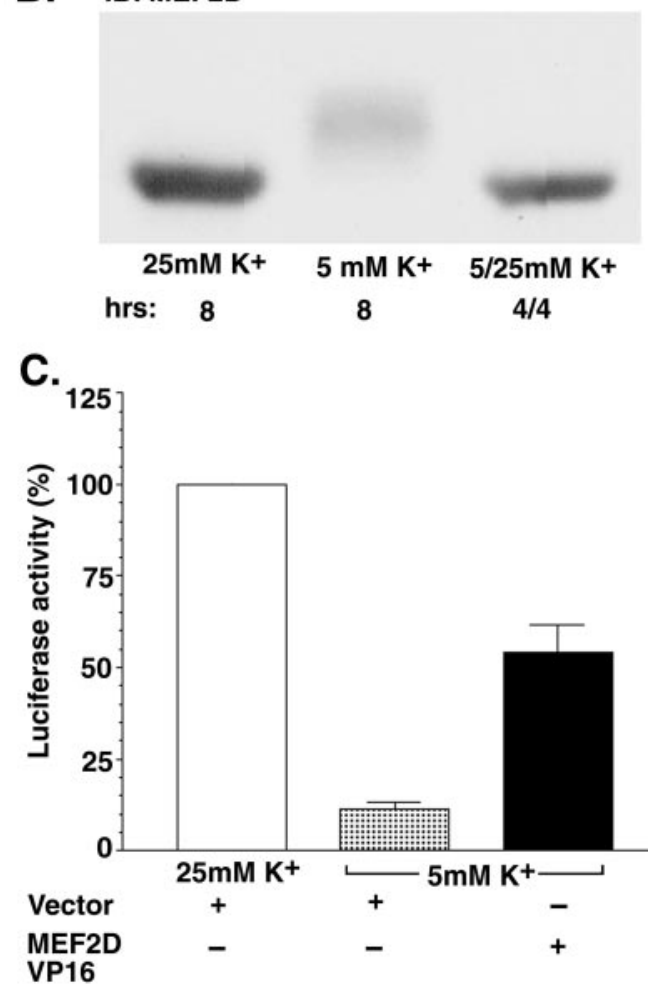

Figure 2. Neurons switched to $5 \mathrm{mM} \mathrm{KCl}$ show enhanced MEF2D phosphorylation and decreased MEF2 transcriptional activity; the readdition of $25 \mathrm{mM} \mathrm{KCl}$ promotes the dephosphorylation of MEF2D and the partial recovery of MEF2 transcriptional activity. $A$, Cerebellar granule neurons (day 6) were transfected with a MEF2-responsive luciferase reporter and $\mathrm{pCMV}-\beta$-gal. After transfection $(2 \mathrm{hr})$ the neurons were placed in serum-free medium containing either 25 or $5 \mathrm{~mm} \mathrm{KCl}$ for $8 \mathrm{hr}$. In addition, some cells were incubated for $4 \mathrm{hr}$ in $5 \mathrm{~mm} \mathrm{KCl}$, followed by the readdition of $25 \mathrm{~mm} \mathrm{KCl}$ for an additional $4 \mathrm{hr}$. Then luciferase and $\beta$-galactosidase activities were determined as described in Materials and Methods. $B$, Cerebellar granule neurons were incubated as described in $A$, and the phosphorylation status and relative quantity of MEF2D were determined by immunoblot $(I B)$ analysis. $C$, Cerebellar granule neurons were transfected with a MEF2-responsive luciferase reporter and $\mathrm{pCMV}$ $\beta$-gal in the absence or presence of pCMV-MEF2D-VP16. After $4 \mathrm{hr}$ the luciferase and $\beta$-galactosidase activities were determined. Data are expressed as a percentage of control neurons grown in $25 \mathrm{~mm} \mathrm{KCl}$ and are the mean $\pm \operatorname{SEM}(n=3)$.

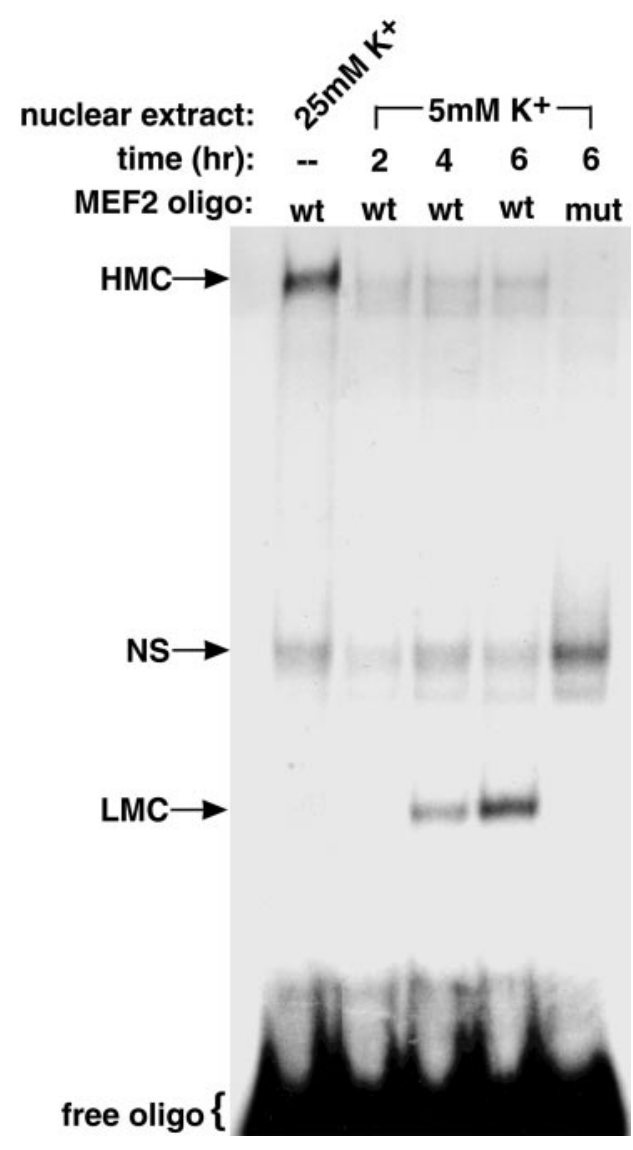

Figure 3. MEF2 DNA binding activity is decreased in apoptotic neurons. Cerebellar granule neurons (day 7) were placed in serum-free medium containing 25 or $5 \mathrm{~mm} \mathrm{KCl}$. After the indicated times, nuclear extracts were prepared, and gel mobility shift assays were performed with a double-stranded ${ }^{32} \mathrm{P}$-labeled consensus $(w t)$ or mutant (mut) MEF2 oligomer. $N S$, Nonspecific protein/DNA complex; $H M C$, high-mobility complex; $L M C$, low-mobility complex.

$4 \mathrm{hr}$ in $5 \mathrm{~mm}$ potassium (Fig. 2B, lane 1 vs lane 3). Finally, transfection of neurons with MEF2D-VP16, a constitutively active mutant of MEF2D, attenuated the decline of MEF2 luciferase activity during potassium withdrawal (Fig. $2 C$ ). The decrease in MEF2 transcriptional activity was not attributable to a nonselective effect of cell death, because the transcriptional activity of AP-1 measured with an AP-1 luciferase reporter construct was increased by $30 \%$ under the same conditions by which the MEF2 transcriptional activity decreased (data not shown).

\section{DNA binding of MEF2A and MEF2D is regulated by extracellular potassium}

To determine whether the DNA binding activity of MEF2 proteins was regulated during induction of the apoptosis of cerebellar granule neurons, we performed electrophoretic mobility shift assays (EMSAs) by using wild-type and mutant MEF2 doublestranded oligonucleotides. Nuclear extracts from cerebellar granule neurons cultured in medium containing $25 \mathrm{~mm} \mathrm{KCl}$ demonstrated one specific high-mobility protein-DNA complex, HMC (Fig. 3). Extracts from neurons cultured in $5 \mathrm{~mm} \mathrm{KCl}$ revealed a decrease in the HMC that was detected as early as $2 \mathrm{hr}$ after the potassium was lowered. In addition to the decrease in the HMC associated with the apoptotic response, a new lower-mobility MEF2-DNA binding complex, LMC, was detected in extracts 


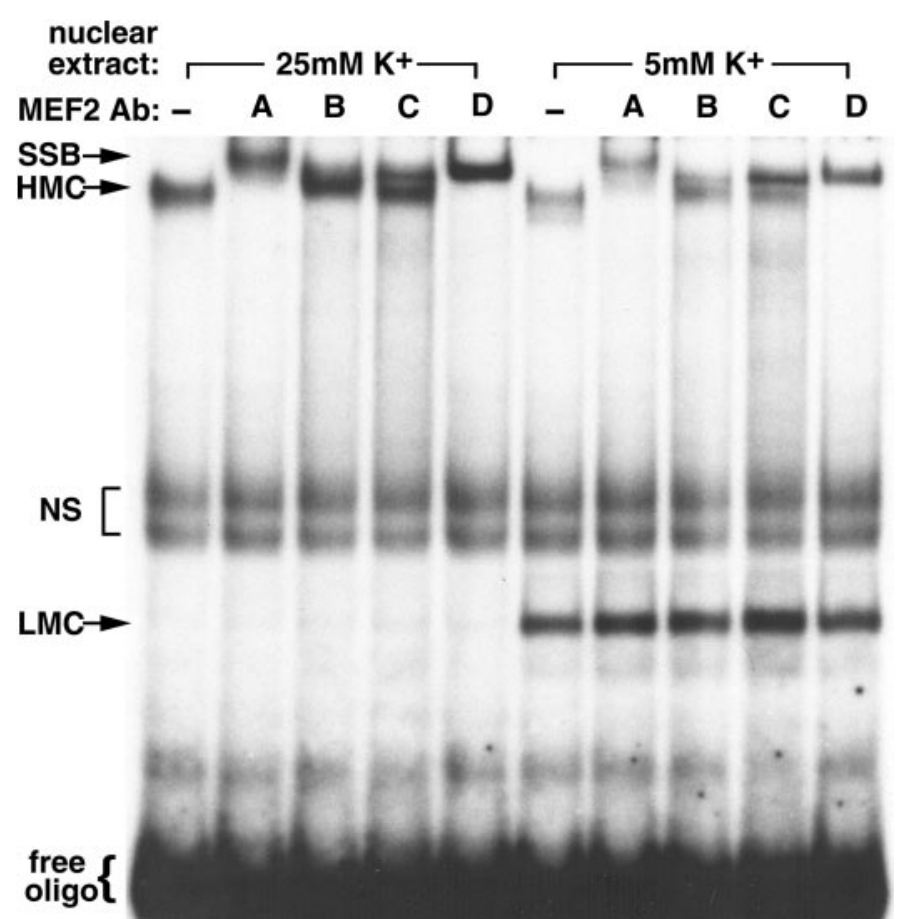

Figure 4. MEF2A and MEF2D are the major MEF2s in the highmolecular-weight DNA binding complex. Cerebellar granule neurons (day 7) were placed in serum-free medium containing 25 or $5 \mathrm{mM} \mathrm{KCl}$. After $4 \mathrm{hr}$, nuclear extracts were prepared, and supershift gel mobility shift assays were performed with a double-stranded ${ }^{32} \mathrm{P}$-labeled consensus MEF2 oligomer in the absence or presence of MEF2 antibodies. Note that the lower-molecular-weight complex did not shift with MEF2 antibodies. $S S B$, Supershifted band; $H M C$, high-mobility complex; $L M C$, low-mobility complex; $N S$, nonspecific protein/DNA complex.

isolated 4 and $6 \mathrm{hr}$ after the media change. Neither the HMC nor the LMC was detected by using a mutant MEF2 oligonucleotide.

EMSAs that used antibodies against MEF2A, B, C, and D proteins were performed to determine which $\mathrm{MEF} 2$ proteins were bound to DNA under control and apoptotic conditions (Fig. 4). In control neurons, antibodies against MEF2A and MEF2D shifted the HMC to a slower migrating band (SSB), whereas antibodies against MEF2B and MEF2C had little effect on the MEF2-DNA complex. Similar results were obtained in apoptotic neurons, although the amount of high-mobility complex was significantly lower than that present in healthy neurons. Interestingly, the LMC was not shifted by any of the MEF2 antibodies. Because each of the antibodies was raised against the $\mathrm{C}$ terminus, but not the $\mathrm{N}$ terminus DNA binding domain of MEF2 proteins (Fig. 5A), we questioned whether MEF2A and MEF2D were degraded during apoptosis to yield MEF2 fragments that bound DNA but did not interact with the antibodies.

\section{Degradation of MEF2A and MEF2D during apoptosis of cerebellar granule neurons}

To test the hypothesis that MEF2 proteins were degraded during apoptosis, we performed Western analysis and exposed the transferred proteins to film for longer periods of time than in previous experiments. The results showed that, within $1 \mathrm{hr}$ of inducing apoptosis, MEF2D was phosphorylated, as shown previously, and a smaller-molecular-weight MEF2D fragment appeared (Fig. $5 B$ ). The fragment, usually a broad band, had an apparent molecular weight of $40-45 \mathrm{kDa}, \sim 15 \mathrm{kDa}$ less than full-length MEF2D.

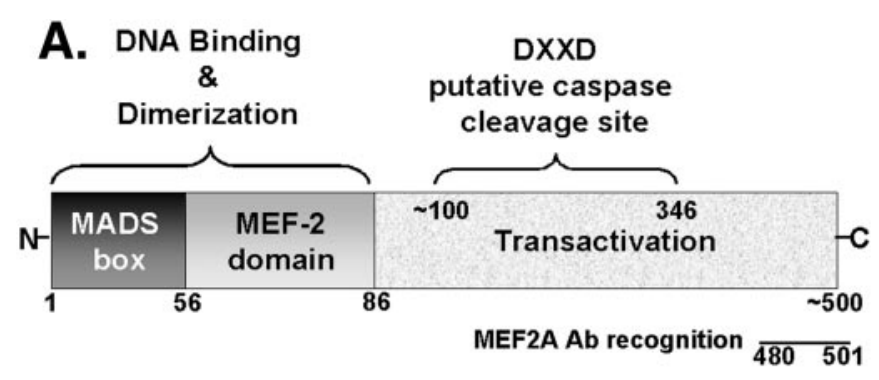

MEF2D Ab recognition $\overline{346}$ 511

B.

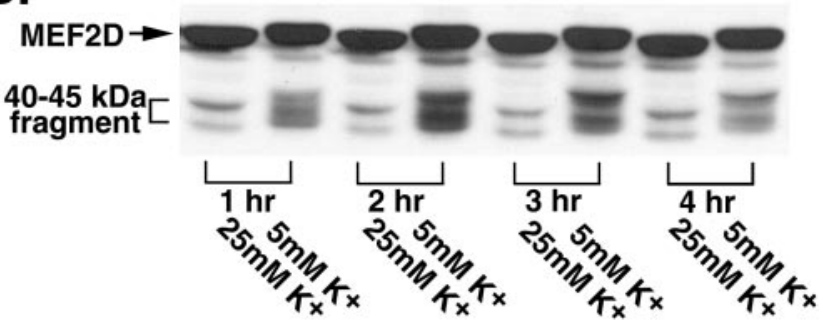

C.

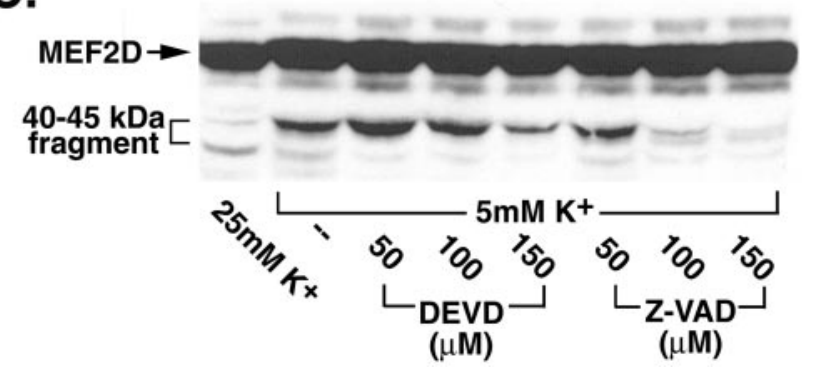

Figure 5. MEF2D is cleaved by a caspase-mediated pathway during apoptosis. $A$, Domain structure of the MEF2 proteins, including the MEF2A and MEF2D antibody recognition motifs and the putative caspase cleavage region. $B$, Cerebellar granule neurons (day 7) were placed in serum-free medium containing 25 or $5 \mathrm{~mm} \mathrm{KCl}$. At the indicated times, Western analysis was performed with $12 \%$ SDS-acrylamide gels and specific MEF2D antibodies. $C$, Neurons were placed in serum-free medium containing 25 or $5 \mathrm{mM} \mathrm{KCl}(4 \mathrm{hr})$ in the absence or presence of various concentrations of the caspase-3-specific inhibitor DEVD or the pan-caspase inhibitor Z-VAD. Brackets indicate a lower-molecular-weight cleavage product recognized by the C-terminal MEF2D antibody.

Analysis of various MEF2 sequences (rat MEF2D and mouse MEF2D1a and MEF2A) revealed several putative caspase cleavage sites (DXXD) between the DNA binding domain and the antibody recognition domain (amino acids 100-346) (Fig. 5A). To determine whether the MEF2 fragment that was generated during apoptosis resulted from caspase cleavage, we performed experiments to assess whether caspase inhibitors blocked formation of the MEF2D fragment. DEVD, a caspase-3-specific inhibitor, and Z-VAD, a nonselective caspase inhibitor, blocked the formation of the MEF2D fragment in a dose-dependent manner (Fig. $5 C)$. Z-VAD was much more effective and potent than DEVD in preventing cleavage of $\mathrm{MEF} 2 \mathrm{D}$, suggesting that an upstream caspase rather than the downstream caspase- 3 might be involved in cleaving MEF2D. Consistent with this idea was the finding that the cleavage of MEF2D occurred much earlier than the activation 


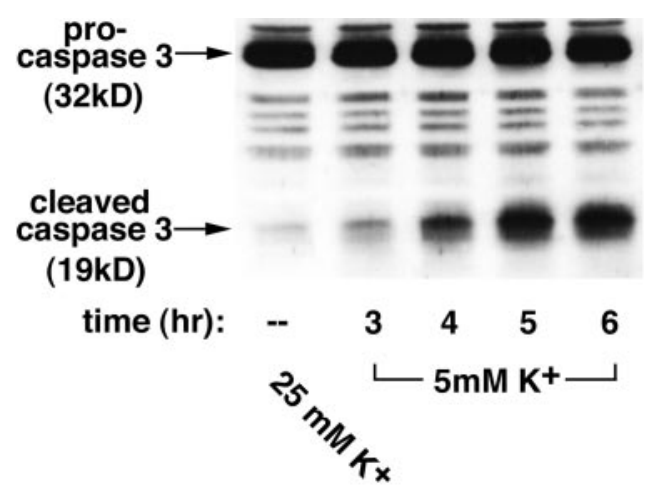

Figure 6. Caspase-3 activation in rat cerebellar granule neurons. Cerebellar granule neurons (day 7) were placed in serum-free medium containing 25 or $5 \mathrm{~mm}$ potassium. At the indicated times, Western analysis was performed with 15\% SDS-acrylamide gels and an antibody that detects pro-caspase- 3 and an active caspase- 3 cleavage product.

of caspase-3, which was maximal at 5-6 hr after the induction of apoptosis (Fig. 6).

\section{Caspase inhibitor blocks formation of the low-mobility protein-DNA complex}

Blockade of MEF2D cleavage by caspase inhibitors supported the hypothesis that during apoptosis MEF2D is cleaved to generate a $\mathrm{N}$-terminal DNA binding fragment, which is not recognized by antibodies directed against the regulatory domain, and a C-terminal fragment that is recognized by Western blotting. To test this hypothesis directly, we treated neurons with and without a caspase inhibitor before the EMSAs (Fig. 7). As shown previously in nuclear extracts from control neurons grown in $25 \mathrm{~mm}$ $\mathrm{KCl}$, the LMC was very low (Fig. 7, lane 1). After $4 \mathrm{hr}$ of apoptosis induced by lowering the extracellular potassium to 5 mM, the LMC was abundant (Fig. 7, lane 2). The caspase inhibitor $\mathrm{Z}$-VAD, added at the time of the medium change, prevented the formation of the lower-molecular-weight complex (Fig. 7, lane 3). In addition, DVED and YVAD (a caspase-1-selective inhibitor) were only partially effective at inhibiting the formation of the low-molecular-weight complex (data not shown). Together, these data suggest that MEF2D and MEF2A are cleaved by a caspasesensitive pathway to generate $\mathrm{N}$-terminal fragments that bind to DNA but are not recognized by antibodies directed to the $\mathrm{C}$ terminus of each of these proteins.

\section{The $\mathrm{N}$-terminal MEF2 fragment can act as a dominant- negative transcription factor}

Cleavage of MEF2 between the DNA binding domain and the antibody recognition domain would separate the DNA binding domain from the transactivation domain. To test the possibility that the N-terminal truncated fragment could act in a dominantnegative manner to block both the DNA binding and transcriptional activity of MEF2, we transfected neurons with MEF2DVP16 in the absence or presence of increasing amounts of truncated MEF2A131. The expression plasmid MEF2D-VP16 encodes the DNA binding domain of mouse MEF2D (amino acids 1-92) fused to the transcriptional activation domain of VP16 (amino acids 412-490) under control of a CMV promoter. Its use as a constitutively active transcription factor has been reported previously (Han and Prywes, 1995). MEF2A131 encodes mouse MEF2A that is truncated at position 131, leaving the DNA binding domain intact, and is highly homologous to the corresponding region of MEF2D. After cotransfection of these

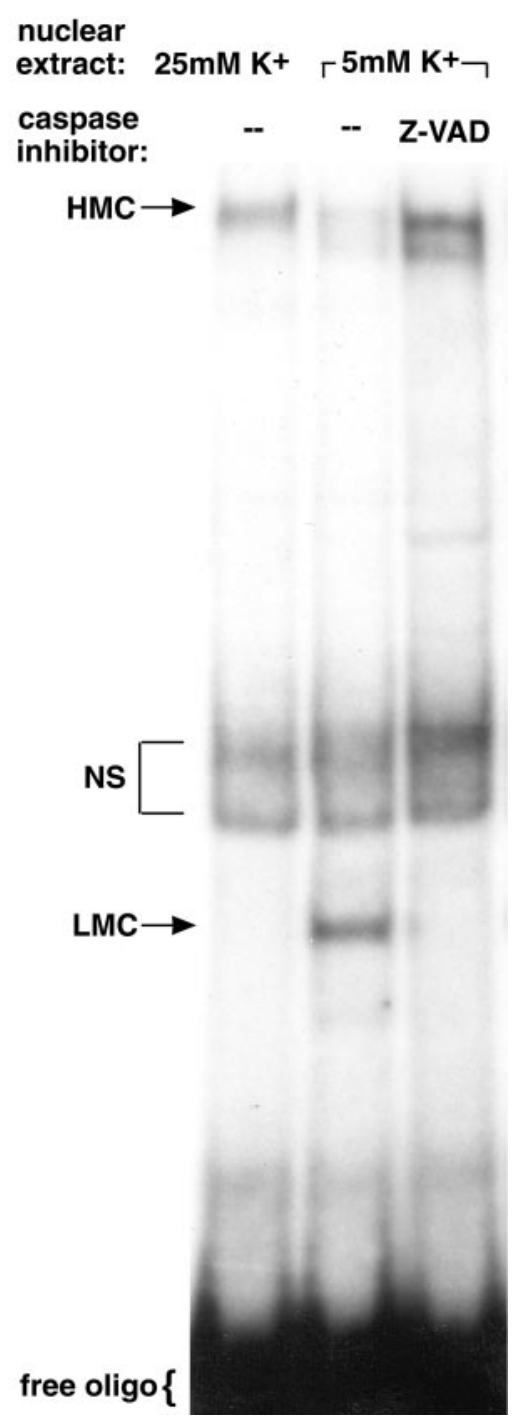

Figure 7. Formation of the lower-molecular-weight protein/DNA binding complex is prevented by caspase inhibition. Cerebellar granule neurons (day 7) were placed in serum-free medium containing 25 or $5 \mathrm{~mm}$ $\mathrm{KCl}$ in the absence or presence of $100 \mu \mathrm{M}$ pan-caspase inhibitor (Z-VAD). After $4 \mathrm{hr}$, nuclear extracts were prepared, and gel mobility shift assays were performed with a double-stranded ${ }^{32} \mathrm{P}$-labeled consensus MEF2 oligomer. $H M C$, High-mobility complex; $L M C$, low-mobility complex; $N S$, nonspecific protein/DNA complex.

two expression plasmids, transcriptional activity was determined with the MEF2 luciferase reporter plasmid (Fig. 8A). As observed previously, neurons incubated in $5 \mathrm{~mm}$ potassium had low MEF2 transcriptional activity. However, the expression of a constitutively active mutant of MEF2D (MEF2D-VP16) maintained high MEF2 transcriptional activity even in the presence of $5 \mathrm{~mm}$ potassium. When the VP16 mutant of MEF2D $(1 \mu \mathrm{g})$ was expressed in the presence of increasing concentrations of truncated MEF2A131 (1-3 $\mu \mathrm{g}$ of DNA), the N-terminal MEF2 fragment blocked MEF2 luciferase activity in a dose-dependent manner (Fig. 8A). These data indicate that a truncated MEF2 can block the DNA binding and activity of MEF2 competitively. The consequence of the expression of truncated MEF2 on neuronal apoptosis is seen in Figure $8 \mathrm{~B}$. In these experiments, neurons were transfected with the control vector, MEF2D-VP16, or MEF2D-VP16 in the presence of increasing amounts of trun- 


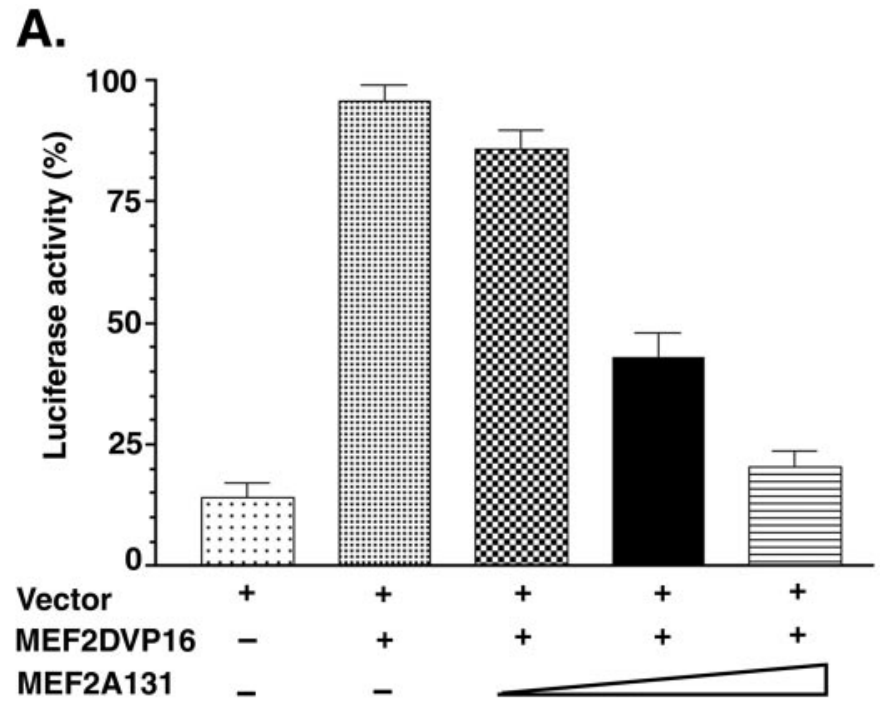

B.

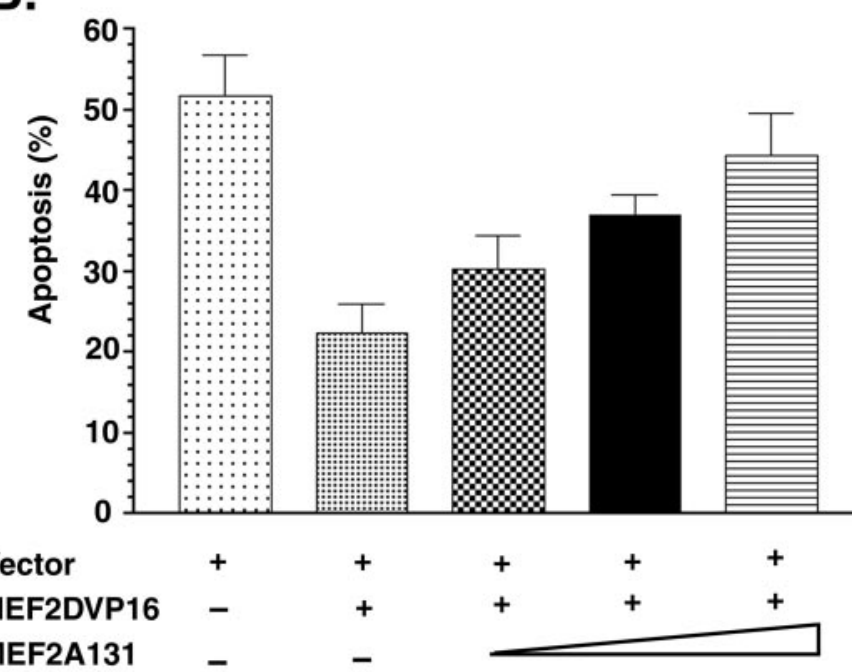

Figure 8. The $\mathrm{N}$ terminus of MEF2 antagonizes MEF2 activity and MEF2-mediated neuronal survival. $A$, Cerebellar granule neurons (day 6) were transfected with a MEF2-responsive luciferase reporter and pCMV$\beta$-gal in the absence or presence of $1 \mu \mathrm{g}$ of MEF2D-VP16 and MEF2A131 (1-3 $\mu \mathrm{g})$. After transfection (2 hr) the neurons were placed in serum-free medium containing $5 \mathrm{~mm} \mathrm{KCl}$. After $4 \mathrm{hr}$, luciferase and $\beta$-galactosidase activities were determined. Luciferase activity was normalized with respect to that of $\beta$-galactosidase. Data are expressed as percentage of control neurons grown in $25 \mathrm{~mm}$ potassium. Data are the mean \pm SEM $(n=3)$. $B$, Cerebellar granule neurons (day 5) were cotransfected with $\mathrm{pCMV}-\beta$-gal and the indicated expression vector at the concentrations given in $A$. After transfection the neurons were placed in serum-free medium containing $5 \mathrm{~mm} \mathrm{KCl}$ for $16 \mathrm{hr}$ and then fixed and immunostained with a $\beta$-gal antibody. The neurons also were stained with Hoechst 33258. Apoptosis was quantified by scoring the percentage of transfected neurons with condensed or fragmented nuclei. Data are the mean $\pm \operatorname{SEM}(n=3)$. Vector, Empty pcDNA vector.

cated MEF2A131. In neurons maintained in $5 \mathrm{~mm}$ potassium for $16 \mathrm{hr}$ the level of apoptosis was $56 \%$. Transfection of the neurons with MEF2D-VP16 reduced the amount of apoptosis to $\sim 22 \%$. When the truncated MEF2A131 mutant (1-3 $\mu \mathrm{g}$ of DNA) was introduced with MEF2D-VP16 into neurons, the ability of MEF2D-VP16 to block apoptosis was attenuated in a dosedependent manner. These data indicate that the MEF2
$\mathrm{N}$-terminal fragment can act as a dominant-negative transcription factor and antagonize the prosurvival function of MEF2D.

\section{DISCUSSION}

Examination of the temporal and spatial localization of MEF2 proteins in brain has revealed that MEF2 expression coincides with the initiation of postmitotic neuronal maturation (Leifer et al., 1993, 1994; McDermott et al., 1993; Ikeshima et al., 1995; Lyons et al., 1995; Mao et al., 1999). For example, in the developing cerebral cortex, MEF2C immunoreactivity is present in the cortical plate and is not found in the intermediate zone or ventricular zone (Mao et al., 1999). At 14 weeks of gestation, MEF2C immunoreactivity is present in cell nuclei throughout the cortical plate. Subsequently, MEF2C immunoreactivity develops a bilaminate and then a trilaminate distribution and ultimately is expressed preferentially in layers II, IV, and VI of mature neocortex (Leifer et al., 1994). These findings suggest a role for $\mathrm{MEF} 2 \mathrm{C}$ in postmitotic neuronal differentiation, in particular in the development of certain cortical layers.

In the cerebellum, MEF2A and MEF2D mRNA levels dramatically increase at $\sim$ P9, reach a peak at P15-P18, and stay high in adults (Leifer et al., 1994; Ikeshima et al., 1995; Lin et al., 1996; Mao and Wiedmann, 1999). This time course of MEF2 expression coincides with the expression of the $\mathrm{GABA}_{\mathrm{A}}$ receptor $\alpha 6$ subunit mRNA, a marker for the differentiation of mature cerebellar granule neurons. Immunohistochemical staining reveals that MEF2 protein expression occurs primarily in the internal granule cell layer of the cerebellum (Ikeshima et al., 1995). During postnatal development, differentiated granule neurons generated in the external germinal layer migrate to the internal granule layer where they are innervated by mossy fiber axons. There is considerable loss of granule neurons during this process and it is thought that the survival of granule neurons is regulated by depolarization-induced mechanisms during this time period.

Postmitotic granule neurons derived from neonatal rat can be maintained readily in vitro in their fully differentiated state if they are depolarized with a high extracellular concentration of potassium (D’Mello et al., 1993; Miller et al., 1997). If the extracellular potassium concentration is reduced, granule neurons undergo programmed cell death with classic morphological and biochemical features of apoptosis. These characteristics, along with the abundance and high degree of homogeneity, make cultured granule neurons an excellent model to examine the role of MEF2 proteins in depolarization-dependent neuronal survival.

In this report we have defined a novel mechanism by which the activity and levels of MEF2 proteins are regulated during apoptosis of cerebellar granule neurons. We also have shown that $\mathrm{MEF} 2$ proteins are regulated in an isotype-specific manner. All four MEF2 isoforms (A, B, C, and D) were detected by immunoblot analysis in rat cerebellar granule neurons. However, in agreement with results from immunocytochemistry and in situ hybridization (Ikeshima et al., 1995; Lyons et al., 1995), MEF2A and MEF2D were the most prominent MEF2 proteins detected in the cultured cerebellar granule neurons when equal amounts of total protein were analyzed by Westerns (data not shown). MEF2A and MEF2D appear to be responsible for most, if not all, of the MEF2 DNA binding activity in viable cerebellar granule neurons. When granule neurons are induced to undergo apoptosis by lowering potassium, endogenous MEF2A and MEF2D, but not $\mathrm{MEF} 2 \mathrm{~B}$ and $\mathrm{MEF} 2 \mathrm{C}$, are phosphorylated. Phosphorylation is accompanied by a decrease in MEF2 transcriptional activity, and both effects are reversed by the readdition of depolarizing potas- 


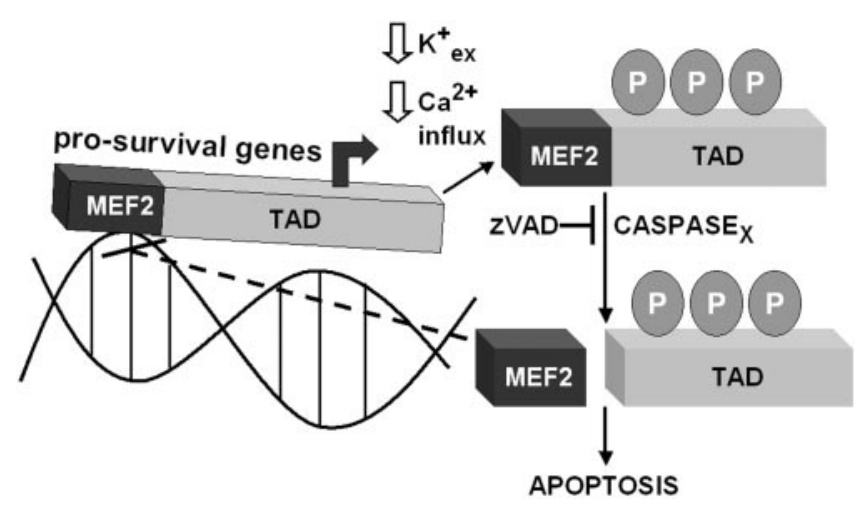

Figure 9. The regulation of MEF2 proteins during apoptosis of rat cerebellar granule neurons. When granule neurons are induced to undergo apoptosis by lowering extracellular potassium to $5 \mathrm{~mm}$, endogenous MEF2D and MEF2A (data not shown) are phosphorylated. Phosphorylation of MEF2D induced by decreasing calcium influx not only leads to decreased DNA binding but also is associated with a caspase-dependent cleavage of MEF2D. The caspase involved in cleaving MEF2D remains to be identified. The cleavage of MEF2D results in an N-terminal fragment ( $\sim 100$ amino acids long) that retains its DNA binding capacity, is not recognized by $\mathrm{C}$-terminal antibodies, and lacks the transactivation domain. The MEF2 N-terminal fragment is capable of blocking the activity of MEF2D, thus acting as a dominant-negative transcription factor. The decline in MEF2 activity because of decreased DNA binding and formation of a dominant-inactive MEF2 fragment leads to apoptosis.

sium. The most novel findings of the present study show that the phosphorylation of MEF2D that is induced by decreasing calcium influx not only correlates with decreased DNA binding but also is associated with a direct or indirect caspase-dependent cleavage of MEF2D (Fig. 9). The cleavage of MEF2D results in a N-terminal fragment ( $\sim 100$ amino acids long) that retains its DNA binding capacity, is not recognized by $\mathrm{C}$-terminal antibodies, and lacks the transactivation domain. The MEF2 N-terminal fragment is capable of blocking the activity of MEF2D, thus acting as a dominant-negative transcription factor. The decline in MEF2 activity resulting from decreased DNA binding and formation of a dominant-inactive MEF2 fragment appears to be sufficient to mediate execution of the apoptotic process. Overexpression of a constitutively active MEF2D that does not get cleaved prevents the loss in MEF2 transcriptional activity during apoptosis and protects against apoptosis that is induced by lowering membrane depolarization and calcium influx.

The signaling pathways responsible for the changes in the phosphorylation state of MEF2 could involve an increase in the activity of a calcium-sensitive kinase, a decrease in the activity of a calcium-sensitive phosphatase, or both. Mao and Wiedman (1999) recently reported similar data that MEF2A is hyperphosphorylated when calcium influx is decreased or when the protein phosphatase calcineurin is inhibited in cerebellar granule neurons. Although other isoforms were not examined in the previous study, the data suggest that enhanced phosphorylation of MEF2A and MEF2D seen on lowering extracellular potassium is likely to be attributable to decreased activity of the calcium-dependent phosphatase calcineurin. Furthermore, because MEF2B and $\mathrm{MEF} 2 \mathrm{C}$ did not undergo hyperphosphorylation in response to lowering extracellular potassium, the data indicate that MEF2A and MEF2D are regulated post-translationally in an isotypespecific manner in cerebellar granule neurons.

The putative phosphorylation sites described in this study are functionally distinct from the previously described phosphoryla- tion sites that enhance MEF2 transcriptional activity. Some MEF2 isoforms directly interact with p38 MAP kinase and ERK5/BMK1 and are phosphorylated by both protein kinases (Kato et al., 1997; Yang et al., 1998; Ornatsky et al., 1999; Zhao et al., 1999). Phosphorylation of MEF2 proteins by p38 MAP kinase and ERK5 stimulates transcriptional activity. The increased transcriptional activity could involve changes in protein conformation that enhance interaction with the transcriptional machinery. Alternatively, phosphorylation might be required for the recruitment of an essential transcriptional cofactor or release of a repressor. In support of the latter mechanism, histone deacetylases (HDACs) have been shown to repress the transcriptional activity of MEF2s (Miska et al., 1999; Lemercier et al., 2000; Lu et al., 2000a,b; Youn et al., 2000). Phosphorylation of HDACs by the calcium-sensitive protein kinase CaMK results in the dissociation of HDACs and the unmasking of transcriptional activity.

Other studies in T-cells have mapped a calcineurin-dependent induction of the nur77 promoter to a putative MEF2 DNA binding site (Youn et al., 1999). Although the transcriptional activity of MEF2 in activated T-cells requires calcium signals, its DNA binding activity seems to be constitutive and insensitive to changes in calcium. Again, the data are in contrast to the results of this study in which decreases in intracellular calcium signaling resulted in decreased DNA binding and transcriptional activity. The antibodies used in T-cells examining nur77 promoter activity did not distinguish between MEF2 isoforms. This raises the possibility that the discrepancy may be attributable to differential regulation of the various MEF2 isoforms and/or the presence of cell type-specific accessory proteins.

In summary, the complexities in MEF2-regulated gene expression have been advanced primarily from studies in muscle and T-cells. In the present study we have delineated a novel phosphorylation signaling pathway associated with DNA binding, transcriptional activity, and degradation of neuronal MEF2 proteins. The data in this study also support the hypothesis that MEF2A and MEF2D regulate neuronal survival in the cerebellum, particularly in response to depolarization-induced signals that are important during development.

\section{REFERENCES}

Amacher SL, Buskin JN, Hauschka SD (1993) Multiple regulatory elements contribute differentially to muscle creatine kinase enhancer activity in skeletal and cardiac muscle. Mol Cell Biol 13:2753-2764.

D’Mello SR, Galli C, Ciotti T, Calissano P (1993) Induction of apoptosis in cerebellar granule neurons by low potassium: inhibition of death by insulin-like growth factor I and cAMP. Proc Natl Acad Sci USA 23:10989-10993.

Firulli AB, Miano JM, Bi W, Johnson AD, Casscells W, Olson EN, Schwarz JJ (1996) Myocyte enhancer binding factor-2 expression and activity in vascular smooth muscle cells. Association with the activated phenotype. Circ Res 78:196-204.

Han TH, Prywes R (1995) Regulatory role of MEF2D in serum induction of the c-jun promoter. Mol Cell Biol 15:2907-2915.

Ikeshima H, Imai S, Shimoda K, Hata J, Takano T (1995) Expression of a MADS-box gene, MEF2D, in neurons of the mouse central nervous system: implication of its binary function in myogenic and neurogenic cell lineages. Neurosci Lett 200:117-120.

Kato Y, Kravchenko VV, Tapping RI, Han J, Ulevitch RJ, Lee JD (1997) BMK1/ERK5 regulates serum-induced early gene expression through transcription factor MEF2C. EMBO J 16:7054-7066.

Leifer D, Krainc D, Yu YT, McDermott J, Breitbart RE, Heng J, Neve RL, Kosofsky B, Nadal-Ginard B, Lipton SA (1993) MEF2C, a MADS/MEF2-family transcription factor expressed in a laminar distribution in cerebral cortex. Proc Natl Acad Sci USA 90:1546-1550.

Leifer D, Golden J, Kowall NW (1994) Myocyte-specific enhancer binding factor $2 \mathrm{C}$ expression in human brain development. Neuroscience 63:1067-1079.

Lemercier C, Verdel A, Galloo B, Curtet S, Brocard MP, Khochbin S 
(2000) mHDA1/HDAC5 histone deacetylase interacts with and represses MEF2A transcriptional activity. J Biol Chem 275:15594-15599.

Li M, Wang X, Meintzer MK, Laessig T, Birnbaum MJ, Heidenreich KA (2000) Cyclic AMP promotes neuronal survival by phosphorylation of glycogen synthase kinase 3 $\beta$. Mol Cell Biol 20:9356-9363.

Lin X, Shah S, Bulleit RF (1996) The expression of MEF2 genes is implicated in CNS neuronal differentiation. Brain Res Mol Brain Res 42:307-316.

Lu J, McKinsey TA, Nicol RL, Olson EN (2000a) Signal-dependent activation of the MEF2 transcription factor by dissociation from histone deacetylases. Proc Natl Acad Sci USA 97:4070-4075.

Lu J, McKinsey TA, Zhang CL, Olson EN (2000b) Regulation of skeletal myogenesis by association of the MEF2 transcription factor with class II histone deacetylases. Mol Cell 6:233-244.

Lyons GE, Micales BK, Schwarz J, Martin JF, Olson EN (1995) Expression of mef2 genes in the mouse central nervous system suggests a role in neuronal maturation. J Neurosci 15:5727-5738.

Mao Z, Wiedmann M (1999) Calcineurin enhances MEF2 DNA binding activity in calcium-dependent survival of cerebellar granule neurons. J Biol Chem 274:31102-31107.

Mao Z, Bonni A, Xia F, Nadal-Vicens M, Greenberg ME (1999) Neuronal activity-dependent cell survival mediated by transcription factor MEF2. Science 286:785-790.

Martin JF, Miano JM, Hustad CM, Copeland NG, Jenkins NA, Olson EN (1994) A MEF2 gene that generates a muscle-specific isoform via alternative mRNA splicing. Mol Cell Biol 14:1647-1656.

McDermott JC, Cardoso MC, Yu YT, Andres V, Leifer D, Krainc D, Lipton SA, Nadal-Ginard B (1993) hMEF2C gene encodes skeletal muscle- and brain-specific transcription factors. Mol Cell Biol 13:2564-2577

Miller TM, Tansey MG, Johnson Jr EM, Creedon DJ (1997) Inhibition of phosphatidylinositol 3-kinase activity blocks depolarization and insulin-like growth factor I-mediated survival of cerebellar granule cells. J Biol Chem 272:9847-9853.

Miska EA, Karlsson C, Langley E, Nielsen SJ, Pines J, Kouzarides T (1999) HDAC4 deacetylase associates with and represses the MEF2 transcription factor. EMBO J 18:5099-5107.

Molkentin JD, Olson EN (1996) Combinatorial control of muscle development by basic helix-loop-helix and MADS-box transcription factors. Proc Natl Acad Sci USA 93:9366-9373.
Molkentin JD, Firulli AB, Black BL, Martin JF, Hustad CM, Copeland N, Jenkins N, Lyons G, Olson EN (1996) MEF2B is a potent transactivator expressed in early myogenic lineages. Mol Cell Biol 16:3814-3824.

Naya FS, Olson E (1999) MEF2: a transcriptional target for signaling pathways controlling skeletal muscle growth and differentiation. Curr Opin Cell Biol 11:683-688.

Okamoto S, Krainc D, Sherman K, Lipton SA (2000) Antiapoptotic role of the p38 mitogen-activated protein kinase-myocyte enhancer factor 2 transcription factor pathway during neuronal differentiation. Proc Natl Acad Sci USA 97:7561-7566.

Ornatsky OI, Andreucci JJ, McDermott JC (1997) A dominant-negative form of transcription factor MEF2 inhibits myogenesis. J Biol Chem 272:33271-33278

Ornatsky OI, Cox DM, Tangirala P, Andreucci JJ, Quinn ZA, Wrana JL Prywes R, Yu YT, McDermott JC (1999) Post-translational control of the MEF2A transcriptional regulatory protein. Nucleic Acids Res 27:2646-2654.

Shore P, Sharrocks AD (1995) The MADS-box family of transcription factors. Eur J Biochem 229:1-13.

Skerjanc IS, Wilton S (2000) Myocyte enhancer factor 2C upregulates MASH-1 expression and induces neurogenesis in P19 cells. FEBS Lett 472:53-56.

Yang CC, Ornatsky OI, McDermott JC, Cruz TF, Prody CA (1998) Interaction of myocyte enhancer factor 2 (MEF2) with a mitogenactivated protein kinase, ERK5/BMK1. Nucleic Acids Res 26:4771-4777.

Youn HD, Sun L, Prywes R, Liu JO (1999) Apoptosis of T-cells mediated by $\mathrm{Ca}^{2+}$-induced release of the transcription factor MEF2. Science 286:790-793.

Youn HD, Grozinger CM, Liu JO (2000) Calcium regulates transcriptional repression of myocyte enhancer factor 2 by histone deacetylase 4 J Biol Chem 275:22563-22567.

Yu YT, Breitbart RE, Smoot LB, Lee Y, Mahdavi V, Nadal-Ginard B (1992) Human myocyte-specific enhancer factor 2 comprises a group of tissue-restricted MADS-box transcription factors. Genes Dev 6:1783-1798.

Zhao M, New L, Kravchenko VV, Kato Y, Gram H, di Padova F, Olson EN, Ulevitch RJ, Han J (1999) Regulation of the MEF2 family of transcription factors by p38. Mol Cell Biol 19:21-30. 